Department of the Interior

U.S. Geological Survey

\title{
THE LOUISIANA COASTAL GEOGRAPHIC INFORMATION SYSTEM NETWORK (LCGISN): ACCESS TO SPATIAL DATA
}

by

Randolph A. McBride', Donald W. Davis', Farrell W. Jones ${ }^{2}$, Mark R. Byrnes ${ }^{1}$ Dewitt Braud, Jr. ${ }^{3}$, Anthony J. Lewis ${ }^{4}$, and Henry R. Streiffer ${ }^{3}$

\author{
S. Jeffress Williams ${ }^{5}$ \\ USGS Science Officer and Editor
}

Open-File Report 91-622

This report was prepared under contract to the U.S. Geological Survey and has not been reviewed for conformity with USGS editorial standards (or with the North American Stratigraphic Code). Opinions and conclusions expressed herein do not necessarily represent those of the USGS. Any use of trade, product, or firm names is for descriptive purposes only and does not imply endorsement by the U.S. Government.

1 Louisiana Geological Survey, Box G, University Station, Louisiana State University, Baton Rouge, LA 70893

2 CADGIS Research Laboratory, College of Design, Room 216, Louisiana State University, Baton Rouge, 70803

3 Decision Associates Inc., 1276 Sharynwood Drive, Baton Rouge, LA 70808

4 Department of Geography and Anthropology, Louisiana State University, Baton Rouge, LA 70803

5 U.S. Geological Survey, 914 National Center, Reston, VA 22092 


\section{TABLE OF CONTENTS}

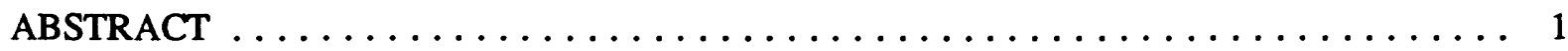

ACKNOWLEDGEMENT $\ldots \ldots \ldots \ldots \ldots \ldots \ldots \ldots \ldots \ldots \ldots \ldots \ldots \ldots \ldots$

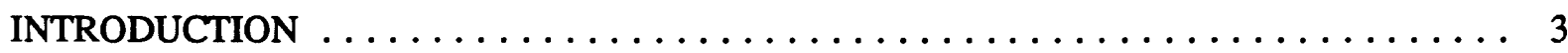

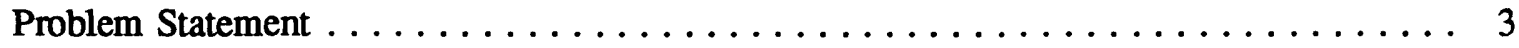

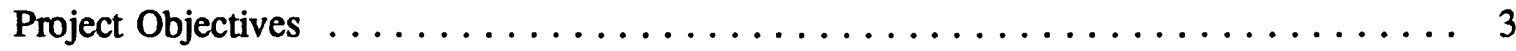

IMPLEMENTATION OF A GEOGRAPHIC INFORMATION SYSTEM $\ldots \ldots \ldots \ldots$

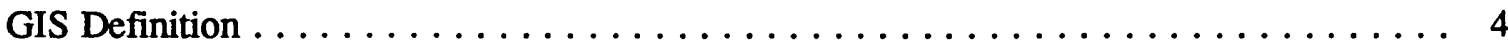

Need for a GIS $\ldots \ldots \ldots \ldots \ldots \ldots \ldots \ldots \ldots \ldots \ldots \ldots \ldots \ldots \ldots \ldots$

Need for a GIS Network $\ldots \ldots \ldots \ldots \ldots \ldots \ldots \ldots \ldots \ldots \ldots \ldots \ldots$

ORGANIZATIONAL FRAMEWORK OF LCGISN $\ldots \ldots \ldots \ldots \ldots \ldots$

YEAR ONE ACCOMPLISHMENTS $\ldots \ldots \ldots \ldots \ldots \ldots \ldots \ldots \ldots \ldots \ldots$

Coordination $\ldots \ldots \ldots \ldots \ldots \ldots \ldots \ldots \ldots \ldots \ldots \ldots \ldots \ldots \ldots \ldots$

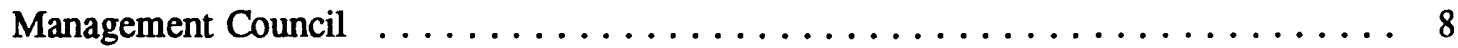

Louisiana GIS Task Force $\ldots \ldots \ldots \ldots \ldots \ldots \ldots \ldots \ldots \ldots \ldots \ldots$

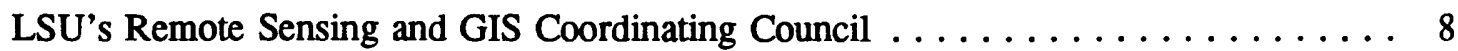

Remote Sensing/GIS Workshop . . . . . . . . . . . . . . . . . . 8

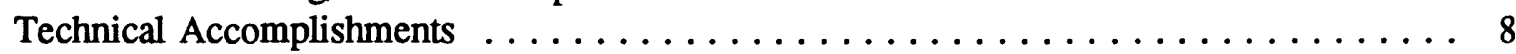

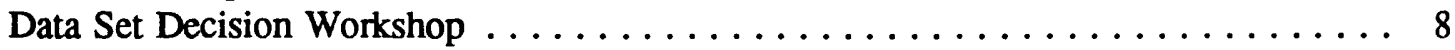

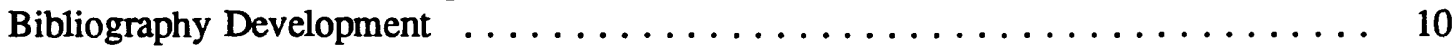

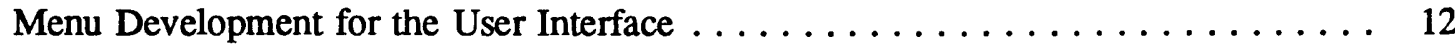

Hardware, Software, and Networking Decisions $\ldots \ldots \ldots \ldots \ldots \ldots \ldots$

Intergraph's Modular GIS Environment (MGE) $\ldots \ldots \ldots \ldots \ldots \ldots \ldots \ldots \ldots$

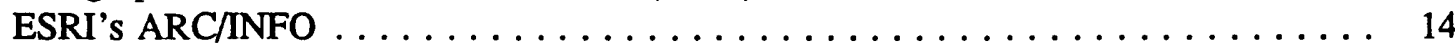

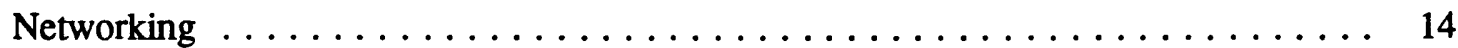

TECHNOLOGY TRANSFER $\ldots \ldots \ldots \ldots \ldots \ldots \ldots \ldots \ldots \ldots \ldots \ldots$

SUMMARY AND FUTURE DIRECTION $\ldots \ldots \ldots \ldots \ldots \ldots \ldots \ldots$

REFERENCES $\ldots \ldots \ldots \ldots \ldots \ldots \ldots \ldots \ldots \ldots \ldots \ldots \ldots \ldots \ldots \ldots \ldots$ 


\begin{abstract}
Average rates of shoreline retreat exceeding $10 \mathrm{~m} / \mathrm{yr}$ and land loss rates of about $100 \mathrm{~km}^{2} / \mathrm{yr}$ are common on the Mississippi River delta and chenier plains. To assess the immense environmental, economic, social, political, and public-safety ramifications for Louisiana and the rest of the Nation posed by these changes, coastal information about their direct and indirect causes needs to be compiled. Although such information exists, Louisiana has neither a central repository for coastal data nor a mechanism by which this information can be accessed or shared locally, regionally, or nationally to help address coastal issues. In response, the Louisiana Geological Survey, the Louisiana State University Department of Geography and Anthropology, the Louisiana State University CADGIS Research Laboratory, and others, through funding provided by the U.S. Geological Survey, are developing the Louisiana Coastal Geographic Information System Network (LCGISN) to provide electronic access to geographic information available from maps, photographs, electronic sensors, videotape surveys, textual attributes, tabular data, and information stored on magnetic media for Louisiana's coastal zone.
\end{abstract}




\section{ACKNOWLEDGEMENT}

Dr. Robert Martin, head of LSU's Special Collections, and the company Information Research are thanked for their assistance. 


\section{INTRODUCTION}

Louisiana has the highest rates of coastal erosion and wetland loss in the United States. Average shoreline retreat rates of over $10 \mathrm{~m} / \mathrm{yr}$ are common (Morgan and Larimore 1957; Penland and Boyd 1981; McBride and others, 1989). Total land loss estimates have reached extreme levels, with rates exceeding $100 \mathrm{~km}^{2} / \mathrm{yr}$ (Gosselink and others, 1979; Gagliano and others, 1981; Davis 1983; Turner and Cahoon 1987; Britsch and Kemp 1990; Penland and others, 1990). These types of coastal changes are caused by a complex interaction of natural and human-induced processes that are not fully understood. With human activities increasing, effective management and monitoring of human and natural resources is critical (Davis, 1983). This is especially true in the coastal zone where a combination of increased coastal development, sea level rise, subsidence, oil spills, and other factors have caused environmental degradation of many coastal areas.

Numerous site-specific and regional studies, as well as mapping projects across many disciplines, have been completed for Louisiana's coastal zone. However, Louisiana has neither a central geographic information system (GIS) to compile this coastal information nor a mechanism by which these data can be accessed locally, regionally, or nationally. As a result, although much coastal information exists, many people are unaware of its existence or unfamiliar with all the different coastal-related repositories scattered throughout Louisiana and hence unable to reach it. For the first time, a central GIS repository and an information-access protocol are being designed and implemented to create the Louisiana Coastal GIS Network (LCGISN). The purpose of LCGISN is not to build another GIS, but instead to develop a system for information access that links existing GIS databases.

\section{Problem Statement}

In response to Louisiana's coastal land loss problem, the U.S. Geological Survey (USGS) began a cooperative research initiative in 1985 with the Louisiana Geological Survey (LGS) and Louisiana State University (LSU) to investigate critical processes of barrier shoreline erosion and wetland loss. This joint effort focused on understanding the problem from a geomorphic, stratigraphic, process, and cultural standpoint. In addition, other local, State, and Federal projects are underway to study and map natural and cultural resources of the coastal zone. The product of these various research activities is the largest accumulation of multidisciplinary coastal information in the United States. A considerable amount of these data have been collected, analyzed, and archived; however, much of the information is not catalogued properly or linked effectively. Furthermore, the data come in a wide variety of media, including digital maps, high-resolution seismic profiles, vibracores, videotapes, satellite imagery, tabular records, high- and low-altitude photography, and field surveys. Unfortunately, much of the digital data is unknown to other agencies or inaccessible due to software and hardware incompatibility. To organize these diverse, multi-agency datasets into an efficient access system, the USGS has committed funds to establish the LCGISN for data access and retrieval.

\section{Project Objectives}

The primary objectives of the LCGISN are to: 1) improve communication among coastal scientists, planners, and managers and local, State, and Federal agencies, and private groups who need information to address Louisiana's coastal erosion and land loss problems; (2) simplify the integration of environmental data from different sources; (3) eliminate duplication of effort so funds can be spent more efficiently; (4) identify the most important existing databases and incorporate them into the GIS network as digital information; (5) promote networking and digital data exchange among different machines, systems, and institutions that use coastal information; (6) establish standard data exchange formats and data quality standards; (7) develop guidelines for cataloging different media and for establishing data set ancestry; (8) develop a user interface that provides access to spatial data; and (9) assist other organizations in developing effective GIS strategies. 


\title{
IMPLEMENTATION OF A GEOGRAPHIC INFORMATION SYSTEM
}

\author{
GIS Definition
}

The commonly accepted definition of a true GIS is a computer-based system used to capture, store, edit, display, spatially analyze, and output geographically referenced data (Burrough 1986; Korte 1991). This definition encompasses computer-assisted mapping (CAM), computer-aided design and drafting (CADD), automated mapping and facilities management (AM/FM), and others, but each of these geographic information software modules falls short of being a true GIS because of the lack of the essential component of spatial analysis.

Computer-assisted mapping includes CADD and computerized cartography. This technology focuses on 2D/3D engineering design, coordinate definition, transformation, and map production. However, CAM generally is not suited for analyzing map data. In a CAM system, map features (points, lines, polygons, and text) are divided into separate themes, using layers or levels, and referenced to a common geographic coordinate system. Because detailed relationships among map features are not defined, spatial analysis is not possible.

An AM/FM system also is based on CADD technology, and often is used to manage public utility data with emphasis on data storage, retrieval, and reporting. In other words, an attached database enables nongraphic attributes to be linked with graphic ones. As a result, geographic queries are possible but full spatial analysis is not.

In a GIS, the spatial relationships among all data elements are defined. Topological information refers to facts about spatial units and their boundaries (non-graphical attributes) that are unaffected by distortions (Logan and Bryant, 1987). Geographic information software is designed to permit routine examination, transformation, and analysis of spatial and attribute data. Some examples of GIS software packages are Intergraph's Modular GIS Environment (MGE), Modular GIS Analyst, and Modular GIS Imager, ESRI's ARC/INFO; ERDAS; and the U.S. Army Corps of Engineers' GRASS.

\section{Need for a GIS}

Korte (1991) describes four primary advantages of a GIS over traditional methods of natural resource assessment: 1) more secure and better organized map data; 2) elimination of redundant map information and multiple map sets; 3) more efficient and faster map revisions; and 4) ability to search, analyze, and present a large amount of diverse data. In addition, application of this technology provides a mechanism for increased productivity and data integration throughout local, State, and Federal agencies, and private industry. Within this framework, LGS is designing project-specific applications for incorporation with LCGISN. For example, a shoreline change GIS strategy (figure 1) for compilation of map data and analysis of historical trends has been developed to accommodate the extensive shoreline position data set for the outer coast of the Mississippi River delta plain.

\section{Need for a GIS Network}

With increased availability of GIS applications software, more geographic information is processed each day. Managing this growing volume so that access to spatial data is maintained requires powerful computer processing and large computer databases that are linked over a network. Without this capability, the large quantity of spatial data is overwhelming and becomes disorganized and inefficiently accessed. Holmes (1990) discusses the need for better access to and management of geographical information and outlines six reasons for networking: 1) the volume of geographic information is immense, 2) it allows integration of diverse geographic information, 3) more information is gained about an area of interest, 4) it provides an efficient method to manage and monitor human activities, 5) all information is shared equally, and 6) remote access to otherwise unaccessible geographic information is established. As an example of expanding data availability, the Earth Scan Laboratory of LSU's Coastal Studies Institute receives real-time satellite data approximately seven times a day that consists of 840 megabytes of raster data that must be archived. Moreover, aerial photography, video imagery, new maps, and vast quantities of environmental data are compiled or created daily. 


\section{SHORELINE CHANGE GIS STRATEGY}

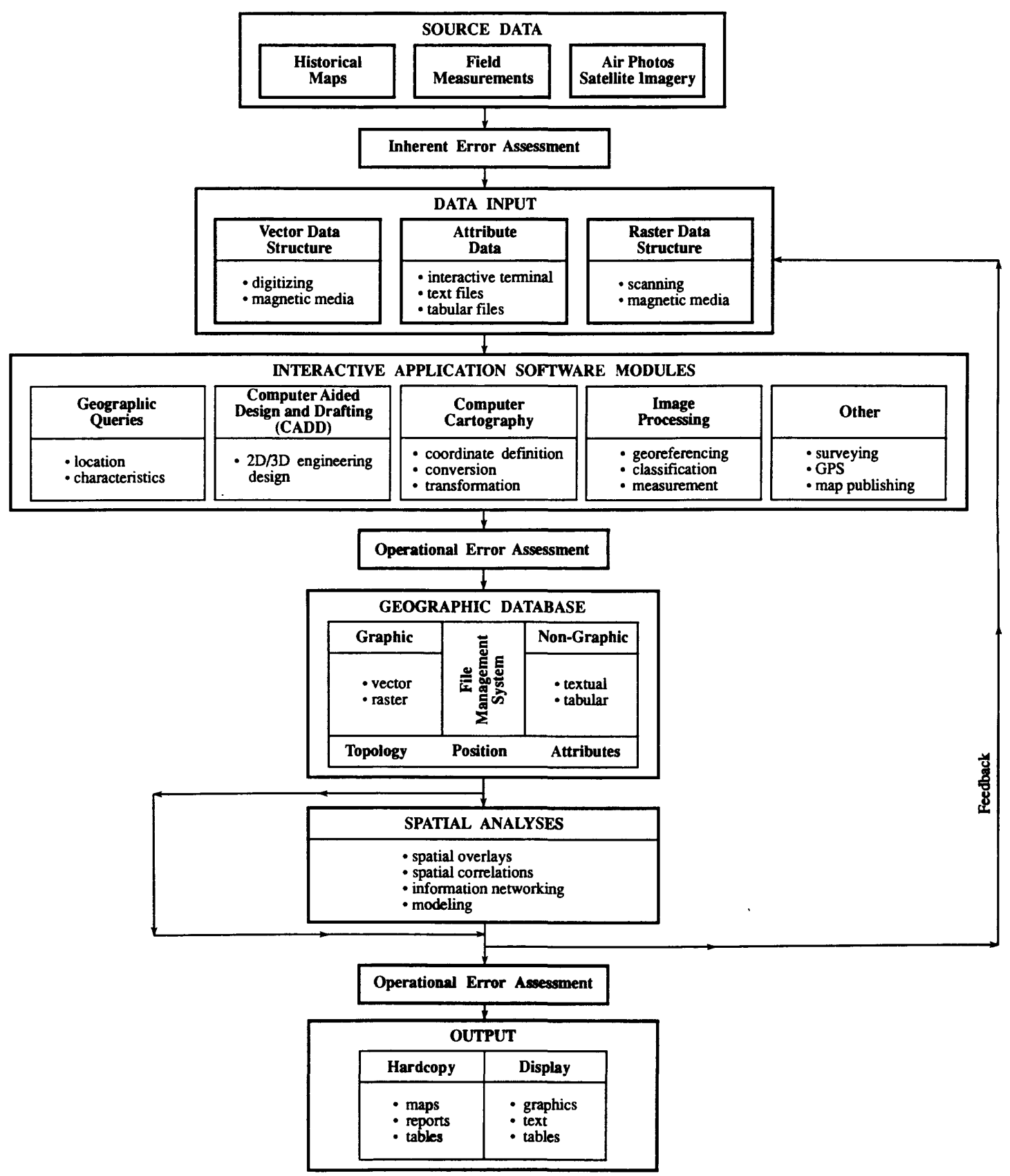

Figure 1. Strategy for compilation and analysis of historical shoreline position data (from Byrnes and others, 1991). 
The integration of geographic information from various formats, software packages, and hardware platforms is a problem, but numerous translation programs now exist or are being developed to help solve these incompatibilities. In addition, digital information from various disciplines need to be integrated.

With computer processing and networked databases, more information can be gained about a specified location. Numerous secondary and tertiary maps, as well as tabular data, can be derived from superimposing independent data sets, such as historical shoreline positions. Distance and areal measurements can be evaluated to quantify the magnitude of change. The influence of cultural activities (e.g., beach fills, coastal structures) can be linked with measured change to propose potential cause-and-effect relationships.

Access by the general public to geographic information and spatial data using modems or networks is made easier with modem technology. This allows more information to be obtained by those people who previously were unable to gain access because of distance and document rarity. Finally, remote access to numerous collections, museums, archives, and repositories from a single computer terminal is possible regardless of media type.

\section{ORGANIZATIONAL FRAMEWORK OF LCGISN}

The LCGISN consists of four major components: 1) a management council, 2) a network core group, 3) a technical GIS group, and 4) two independent advisory groups (figure 2). The Louisiana Geological Survey, is the headquarters for LCGISN.

The management council provides guidance for LCGISN and consists of a representative from each member organization (Louisiana Geological Survey, LSU Department of Geography and Anthropology (G\&A), LSU Computer-Aided Design and GIS (CADGIS) Research Laboratory, LSU Coastal Studies Institute (CSI), LSU Remote Sensing and Image Processing (RSIP) Laboratory, and Coastal Management Division (CMD) of the Louisiana Department of Natural Resources), plus three ad hoc representatives (Office of the Governor, USGS, and United States Fish and Wildlife Service). The management council is chaired by a Louisiana Geological Survey representative. Two more ad hoc members, the U.S. Army Corps of Engineers and the Louisiana GIS Task Force, will be added in the near future. The management council meets regularly to review operational procedures, monitor LCGISN developments, update policies, and consider additions to the network.

The network core group (LGS, CADGIS, G\&A, CSI, RSIP, and CMD) forms the foundation of LCGISN. These participants provide the major coastal data bases, and furnish computer mapping, remote sensing, and GIS expertise; teaching and training facilities; and a large graduate and undergraduate support staff. The technical GIS group meets weekly and is responsible for developing, implementing, and operating the user interface, central GIS facility, and user network. This group consists of experts from the network core group and two private consulting companies, Decision Associates, Inc. and Information Research. Decision Associates specializes in GIS solutions, spatial analysis, and programming; Information Research consist of professional librarians with expertise in computer online searches, standardized bibliographic records, and cataloging. Together, the technical GIS group specializes in computer hardware and software, GIS, remote sensing, computer mapping, coastal geomorphology, geography, and library science. Currently, Modular GIS Environment with Oracle as the relational data base, ARC/INFO/Oracle, and InFoCAD are being tested in-house to determine which one (or more) the LCGISN will utilize.

Two independent advisory groups for LCGISN, the Coastal Users Group and the Technical Applications Group were organized at the Sixth Annual Remote Sensing/GIS Workshop held at Louisiana State University in April 1990. These groups will convene at least once a year at the annual Remote Sensing/GIS Workshop to provide current information on coastal data bases, hardware, software, and projects, and define their relationship to the objectives and future direction of LCGISN. This annual meeting should promote the use and exchange of spatial data and improve communication among individuals, organizations, and agencies working in the Louisiana coastal zone. 


\section{LOUISIANA COASTAL GIS NETWORK}

\section{MANAGEMENT STRUCTURE}

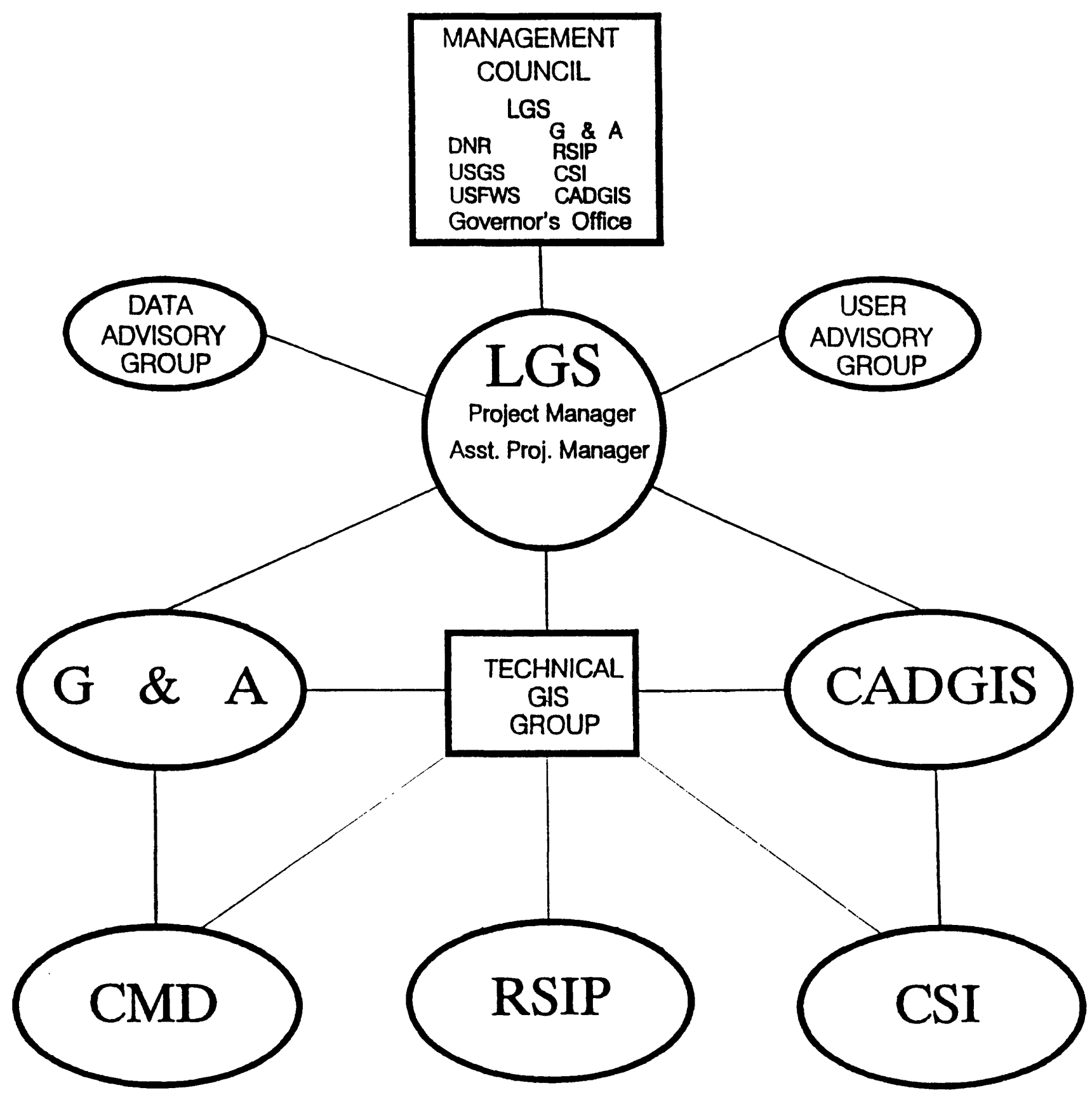

Figure 2. Major components of the Louisiana Coastal GIS Network. 


\section{YEAR ONE ACCOMPLISHMENTS}

During the first year (September 1989 to August 1990), all proposed goals were accomplished and a number of important decisions were made. These achievements are described below in three categories: coordination, technical accomplishments, and hardware, software, and networking decisions.

\section{Coordination}

\section{Management Council}

The council was established in the fall of 1989 and held its first meeting on November 17, 1989. It was attended by 32 people representing numerous Federal, State, and university organizations (table 1). Dr. C.G. "Chip" Groat, Director of the LGS, chaired the meeting. Presentations were made by the LSU Office of Telecommunications on "Computer Networking at LSU", Dr. Carville Earle, Chair of the Department of Geography and Anthropology, on "Importance of Geographic Information Systems", and Mr. S. Jeffress Williams, USGS, on "USGS/LGS Cooperative Research Programs and the Role of the Louisiana Coastal GIS Network". The meeting continued with a review of the project's purpose, participants, organization, and goals, and finished with an open discussion.

\section{Louisiana GIS Task Force}

This task force was started by a group of State agencies interested in coordinating the State's GIS efforts. Sharon Balfour of the Department of Transportation and Development (DOTD) heads the task force. The primary goal is to establish a fully funded statewide GIS. Initially, Chip Groat, Don Davis, and Randy McBride attended the monthly meetings on behalf of the Louisiana Geological Survey. Eventually, Don Davis was appointed the LGS representative. This arrangement insures coordination between LCGISN and the Louisiana GIS Task Force.

\section{LSU's Remote Sensing and GIS Coordinating Council}

This council meets monthly to discuss computer mapping, remote sensing, and GIS activities at LSU. It also coordinates potential GIS contracts among the various laboratories on campus. Don Davis replaced Chip Groat (on leave of absence) as the LGS representative on this council.

\section{Remote Sensing/GIS Workshop}

The Sixth Annual Remote Sensing/GIS Workshop was held in April 1990 at LSU. Tony Lewis (G\&A), Bo Blackmon (CMD), and Larry Hanley (USFWS) were the primary organizers. Randy McBride and Don Davis organized the special half-day session on LCGISN and asked Sharon Balfour (DOTD) and Karen Wicker (Coastal Environments, Inc.) to co-chair the Coastal Users Advisory Group, while Nelson May (LSU Coastal Fisheries Institute) was asked to chair the Technical/Applications Advisory Group. This annual workshop provides a technical forum for communicating ongoing remote sensing/GIS projects in Louisiana's coastal zone, and provides the entire Louisiana remote sensing/GIS community a voice in directing the future of LCGISN.

\section{$\underline{\text { Technical Accomplishments }}$}

\section{Data Set Decision Workshop}

Numerous sets of spatial data on coastal Louisiana exist, but relatively few are in digital format. As a result, a decision was made to identify the most important data sets that should be compiled and digitized for the LCGISN and rank them according to need. Table 2 lists the major data bases identified as significant to users. This identification and ranking was accomplished during a half-day workshop conducted by Decision Associates and attended by 16 representatives from various local, State, Federal, and university organizations who have 
Table 1. Attendees at the management council meeting of the Louisiana Coastal Geographic Information System Network (LCGISN), November 17, 1989.

Sharon J. Balfour

Louisiana Department of Transportation and Development

P.O. Box 94245

Baton Rouge, LA 70804

John Barras

Louisiana Department of Natural Resources

Coastal Management Division

Baton Rouge, LA 70804

Bo Blackmon

Department of Natural Resources

Louisiana Coastal Management Division

P.O. Box 44124

Baton Rouge, LA 70804

Dewitt Braud

Decision Associates

1276 Sharynwood Drive

Baton Rouge, LA 70808-6021

Don Cahoon

Louisiana Geological Survey

Louisiana State University

Box G, University Station

Baton Rouge, LA 70893

David Chambers

Department of Natural Resources

Coastal Restoration Division

Govemor's Office

Baton Rouge, LA 70804

Don Davis

Louisiana Geological Survey

Louisiana State University

Box G, University Station

Baton Rouge, LA 70893

Chip Dodson

Office of Telecommunications

203 David Boyd Hall

Louisiana State University

Baton Rouge, LA 70803

Carville Earie

Department of Geography and Anthropology

235 Howe-Russell Building

Louisiana State University

Baton Rouge, LA 70803

David L. Evans

Remote Sensing and Image Processing Laboratory

Room 3221, CEBA

Louisiana State University

Baton Rouge, LA 70803

Michael Fox

Office of Telecommunications

203 David Boyd Hall

Louisiana State University

Baton Rouge, LA 70803
Chip Groat

Louisiana Geological Survey

Louisiana State University

Box G, University Station

Baton Rouge, LA 70893

Larry Hanley

US Fish and Wildlife Service

National Wetlands Research Center

1010 Gause Boulevard

Slidell, LA 70458

Charies Hariow

Electrical and Computer Engineering

3221 CEBA

Louisiana State University

Baton Rouge, LA 70893

Jack Haynes

Computer-Aided Design and GIS Research

Laboratory

216 New Design Building

Louisiana State University

Baton Rouge, LA 70803

Jack Hill

Remote Sensing and Image Processing

Laboratory

Room 3221, CEBA

Louisiana State University

Baton Rouge, LA 70803

Oscar K. Huh

Coastal Studies Institute

412C Howe/Russell Building

Louisiana State University

Baton Rouge, LA 70803

Farrell Jones

Computer-Aided Design and GIS Research

Laboratory

216 New Design Building

Louisiana State University

Baton Rouge, LA 70803

Nina Lam

Department of Geography and Anthropology

222E Howe/Russell Building

Louisiana State University

Baton Rouge, LA 70803

P. B. Larimore

Department Geography and Anthropology

445 Howe/Russell

Louisiana State University

Baton Rouge, LA 70803

Tony Lewis

Department of Geography and Anthropology

235 Howe-Russell Building

Louisiana State University

Baton Rouge, LA 70803

Robert S. Martin

107 Hill Memorial Library

Louisiana State University

Baton Rouge, LA 70803
L. Nelson, May, Jr.

Coastal Fisheries Institute

Center For Wetland Resources

217 Coastal Studies Building

Louisiana State University

Baton Rouge, LA 70803

Randolph A. McBride

Louisiana Geological Survey

Louisiana State University

Box G, University Station

Baton Rouge, LA 70803

Shea Penland

Louisiana Geological Survey

Louisiana State University

Box G, University Station

Baton Rouge, LA 70893

Doug Rickman

NASA Stennis Space Center

NSTL, Building 1100

Stennis Space Center, MS 39529

Joyce Rolston

Cartographic Information Center 313 Howe/Russel Building

Louisiana State University

Baton Rouge, LA 70803

Lawrence Rouse

Coastal Studies Institute

318 Howe/Russel Building

Louisiana State University

Baton Rouge, LA 70803

Anne Stanton

126 Middleton Library

Louisiana State University

Baton Rouge, LA 70803

Floyd Stayner

US Fish and Wildlife Service

National Wetlands Research Center

1010 Gause Boulevard

Slidell, LA 70458

Henry Streiffer

Decision Associates

1276 Sharynwood Drive

Baton Rouge, LA 70808-6071

S. Jeffress Williams

Office of Energy and Marine Geology

U.S. Geological Survey-MS 914

12201 Sunrise Valley Drive

Reston, VA 22092 
1. spatial index/bibliography of all data

1. U.S. Geological Survey 7.5-minute quadrangle maps

2. water quality and chemistry

3. Wetland Inventory Ecological Characterization maps (U.S. Fish and Wildlife Service)

3. hydrography and hydrology

3. geologic and engineering framework data

3. mineral extraction data and maps (aggregate, oil, gas, sulfur, etc.)

4. land use maps

4. biological survey data

5. bathymetry

5. soil types

6. point-source discharge data

7. land loss maps

8. weather records and maps

8. canal and pipeline data

8. Federal and state physical regulations (permits, violations, mitigation)

9. shoreline change and geomorphology

9. land cover data (thematic mapper)

9. ownership

9. habitat sensitivity maps

10. National Resource Inventory data (Soil Conservation Service)

10. census data (TIGER files)

10. potable water sources

10. recreational use

10. economic zones

11. naturally occurring radiologic material

11. disease mortality

direct interests in Louisiana's coastal zone (table 3). Other data sets, can be identified and added to the data base as appropriate.

A spatial index and bibliography was one of the top-ranked data sets for Louisiana's coastal zone. This emphasizes the fact that public access to maps and spatial information depends on a link among standardized bibliographic records, spatially-indexed maps, and on-line vector or raster data. Professional librarians will assist in establishing a framework for cataloging various media. Their tasks include integration of a key word list and standardized bibliographic records. Additionally, each collection of materials to be included in LCGISN must be reviewed to assess present bibliographic access, location and order of the items, and physical format of the items.

\section{Bibliography Development}

From the Data Set Decision Workshop in November 1989, it was determined public access to maps and spatial information hinges upon an online link to standardized bibliographic records, index maps, and vector and raster data with the ability to automatically access these records. The importance of cataloging and standardization of bibliographic records was realized.

To assist with this task, professional library advice was solicited. In early 1990, Donald Davis and Randy McBride visited Dr. Robert Martin, who is head of Special Collections at LSU and has a particular interest in historical maps. He introduced the design team to the library science's machine-readable cataloging format (MARC), which is the standard cataloging format used by libraries nationally and internationally. MARC also has a special category for cartographic materials. 
Table 3. Attendees at the data set decision workshop of the Louisiana Coastal Geographic Information System Network (LCGISN), November 20, 1989.

\author{
Barney Barrett \\ Louisiana Department of Wildlife \\ and Fisheries \\ P.O. Box 98000 \\ Baton Rouge, LA 70808-9000 \\ (504) 765-2032
}

John Barras

Louisiana Department of Natural Resources

P.O. Box 94396

625 N. 4th Street-Rm. 317

Baton Rouge, LA 70804

(504) $342-4331$

Pete Bourgeois

Louisiana Department of Natural

Resources

P.O. Box 94396

625 N. 4th Street

Baton Rouge, LA 70804

(504) 342-4331

Dewitt Braud

Decision Associates

1276 Sharynwood Drive

Baton Rouge, LA 70808-6071

(504) 769-2117

Jerry J. Daigle

U.S. Soil Conservation Service

3737 Government Street

Alexandria, LA 71302

(318) 473-7822

Don Davis

Louisiana Geological Survey

Louisiana State University

P.O. Box G, University Station

Baton Rouge, LA 70893

(504) 388-3481

David L. Evans

Remote Sensing and Image

Processing Laboratory

Room 3221, CEBA

Louisiana State University

Baton Rouge, LA 70803

(504) 388-6826
Dale Givens

Louisiana Department of

Environmental Quality

Technical Services Division

P.O. Box 82231

Baton Rouge, LA 70884-2231

(504) 765-0062

Larry Hanley

National Wetlands Research Center

US Fish and Wildlife Service

1010 Gause Blvd.

Slidell, LA 70458

(504) 646-7359

Jack Haynes

Computer-Aided Design and GIS

Research Laboratory

216 New Design Building

Louisiana State University

Baton Rouge, LA 70803

(504) 388-8816

Farrell Jones

216 New Design Building

Louisiana State University

Baton Rouge, LA 70803

(504)388-6134

E. Burton Kemp

U.S. Army Corps of Engineers,

New Orleans District

CELMN-ED-FG

P.O. Box 60267

New Orleans, LA 70160-0267

(504) $862-1020$

Tony J. Lewis

Department of Geography and

Anthropology

235 Howe/Russell Building

Louisiana State University

Baton Rouge, LA 70803

(504) 388-6199

E. Jane Luzar

College of Agriculture

Louisiana State University

$246 \mathrm{Ag}$. Administration

Baton Rouge, LA 70803

(504)388-8612
Randolph A. McBride Louisiana Geological Survey

Box G, University Station

Baton Rouge, LA 70893

(504) 388-8612

Lawrence Rouse

Coastal Studies Institute

318 Howe/Russell Building

Louisiana State University

Baton Rouge, LA 70803

(504) 388-2953

Jerry Saunders

U.S. Environmental Protection Agency

1445 Ross Avenue

Dallas, TX

(214) 655-2263

Floyd Stayner

U.S. Fish and Wildlife Service

1010 Gause Blvd.

Slidell, LA 70458

(504) 646-7359

Henry Strieffer

Decision Associates

1276 Sharynwood Drive

Baton Rouge, LA 70808-6971

(504) 769-2117

S. Jeffress Williams

Office of Energy and Marine

Geology

U.S. Geological Survey-MS 914

12201 Sunrise Valley Drive

Reston, VA 22092

(703) 648-6511 
It was evident that the LCGISN needed additional expertise in library science and information exchange. This led to detailed discussions with Information Research, a private consulting company consisting of professional librarians who specialize in expert, in-depth library research, computer database searches, and information access, control, and exchange. During several meetings with the staff of Information Research in the spring of 1990, discussions focused on the MARC format and other GIS-related bibliographic projects, such as Carto-Net, GRIN, GeoIndex, and the USGS cataloging procedures. As a result, Information Research was asked to assist in establishing a framework for cataloging various media (maps, satellite imagery, aerial photography, aerial videotape surveys, textual data). Their task included the integration of a controlled keyword vocabulary and standardized bibliographic records. Additionally, each collection of materials contained in the LCGISN was reviewed to assess present bibliographic access, location, physical format, and other reference items deemed necessary for creating a complete record or bibliographic citation. The design team's exposure to the MARC format made it clear that the bibliographic component of the LCGISN needed to follow a standardized format. The goal is to insure that records for different types of media can be exchanged nationally and internationally, and that these bibliographic records can be linked to spatially indexed maps and imagery.

\section{Menu Development for the User Interface}

Menu development has been the primary area of concern in year one. The technical committee thought it imperative the LCGISN be easily accessible by a wide variety of users. Poor menu design will only complicate presentation and confuse the very individuals the system should assist. Considerable time and effort have been spent creating menus that will provide access to the network data base with minimal effort from the user. Weekly meetings have been held to work on all details of an appropriate menu structure. This cautious and focused approach has produced a comprehensive set of menus that will work with spatial and textual data on a scope that has not been implemented elsewhere.

A literature search was conducted to identify similar systems. Although, several references to map indexing systems were found, investigations showed that some have not been implemented and others work only on personal computers. The designs were found to be lacking in several key areas. It was decided to start from scratch with a new design.

Development of the prototype menu system began with a list of functions essential to the primary role of the LCGISN.

- Provide basic information about the LCGISN and on-line help facilities for using the system.

- Provide a directory of affiliates and associates involved in coastal activities within university, government, private, foundation, and non-profit organizations.

- Maintain computerized bibliographic records of publications pertaining to coastal Louisiana.

- Develop an indexing and geographic search system for maps, photographic products, and imageryreferenced by geographic location, and allow interactive searches specified in a variety of ways from geographic windows, coordinates, or names.

- Provide display and query capabilities of the LCGISN primary GIS digital data bases along with minimal spatial calculations and statistical analyses.

- Provide translation routines to convert data from one GIS system to another.

- Provide projection transformation capabilities.

- Allow for customized procedures and environments.

- Allow for electronic mail and other convenient utilities.

From this outline, the system's functions were described in detail, critiqued, modified, and developed into hierarchical menus that were constructed on the Macintosh HyperCard system. Using MORE, another software 
product on the Macintosh, a tree-type schematic of the prototype system was produced to allow the designers to visualize the connectivity of the network model. A balance of many concept was sought, including:

- user friendliness versus capability of the system

- non-technical verbiage versus precise technical language

- use by non-technical and casual users versus use by researchers

- simplicity versus high level of detail

- generalized interface versus reduced levels and number of menus

- default input versus user control.

The first two menus will introduce the system. The main menu will open the system's files by listing the key subject headings. After a command is selected from the main menu, the user will be able to move through the data by focusing on subtopics listed in the subsequent menus. The topics become more focused on each new men; the end result is a customized path into the data base.

The user will see a display of a reference map and will be able to browse through a file of images and text based on a minimum boundary rectangle, screen display of latitude and longitude, or place name. Image information and textual data will be shown simultaneously.

Once the pathway is established, the key sequence will be saved and can be replicated for future reference. In addition to menus producing text, map information will be available to help locate specific points. Where possible, bibliographic citations will be tagged with geographic coordinates, specific place names or parish (county) names. The graphics data and citations will be available to the user in digital form or as a hard copy.

\section{Hardware, Software, and Networking Decisions}

LCGISN has purchased two GIS systems: Intergraph's Modular GIS Environment and ESRI's ARC/INFO. Below is a short discussion of these two GIS packages, their associated hardware, and their network.

\section{Intergraph's Modular GIS Environment (MGE)}

This software system is running on an Intergraph InterView 32c, Unix-based workstation with $16 \mathrm{MB}$ of primary storage and $250 \mathrm{MB}$ of secondary storage. The workstation has a high-precision, large-format digitizing table (48 x 60") with a large-format Hewlett-Packard 8-color pen plotter (model 7595) for output. MGE is a set of integrated computer software tools, capable of handling all GIS functions in a common, interactive, workstation environment (figure 3). MGE/SX is the base GIS software that provides the primary user interface and basic data management and input tools. Other compatible software modules include photogrammetry, computer cartography, image processing, surveying, terrain modeling and analysis, geotechnical mapping, and subsurface exploration.

The modular characteristic of MGE means that users can expand a system as needed and when financial resources are available. For LCGISN, two modules were bought with the initial acquisition of MGE: Projection Manager and MGE Analyst. Projection Manager provides comprehensive coordinate definition, conversion, and transformation capabilities, for complete flexibility with projection, datum, and ellipsoid definition. It provides several methods for conversion between standard datums such as NAD27 and NAD83. Projection Manager also features least-squares-derived transformation of graphic data based on weighted control points and several transformation models. MGE Analyst uses geographic data to create topological relationships for spatial analyses and for input to other Analyst processes. Historical shorelines, vibracore locations, seismic tracklines, surficial sediment samples, and hard-mineral-resource targets can be used to build integrated, topological data structures. Topological overlays can be quickly created as needed, reducing the number of steps in the process time required for completing GIS planning scenarios. Results derived from queries can be used immediately in further queries or transferred to other Intergraph applications for coastal engineering design or other coastal research projects. Query results can be output as reports, new graphics files, or hardcopy maps. 


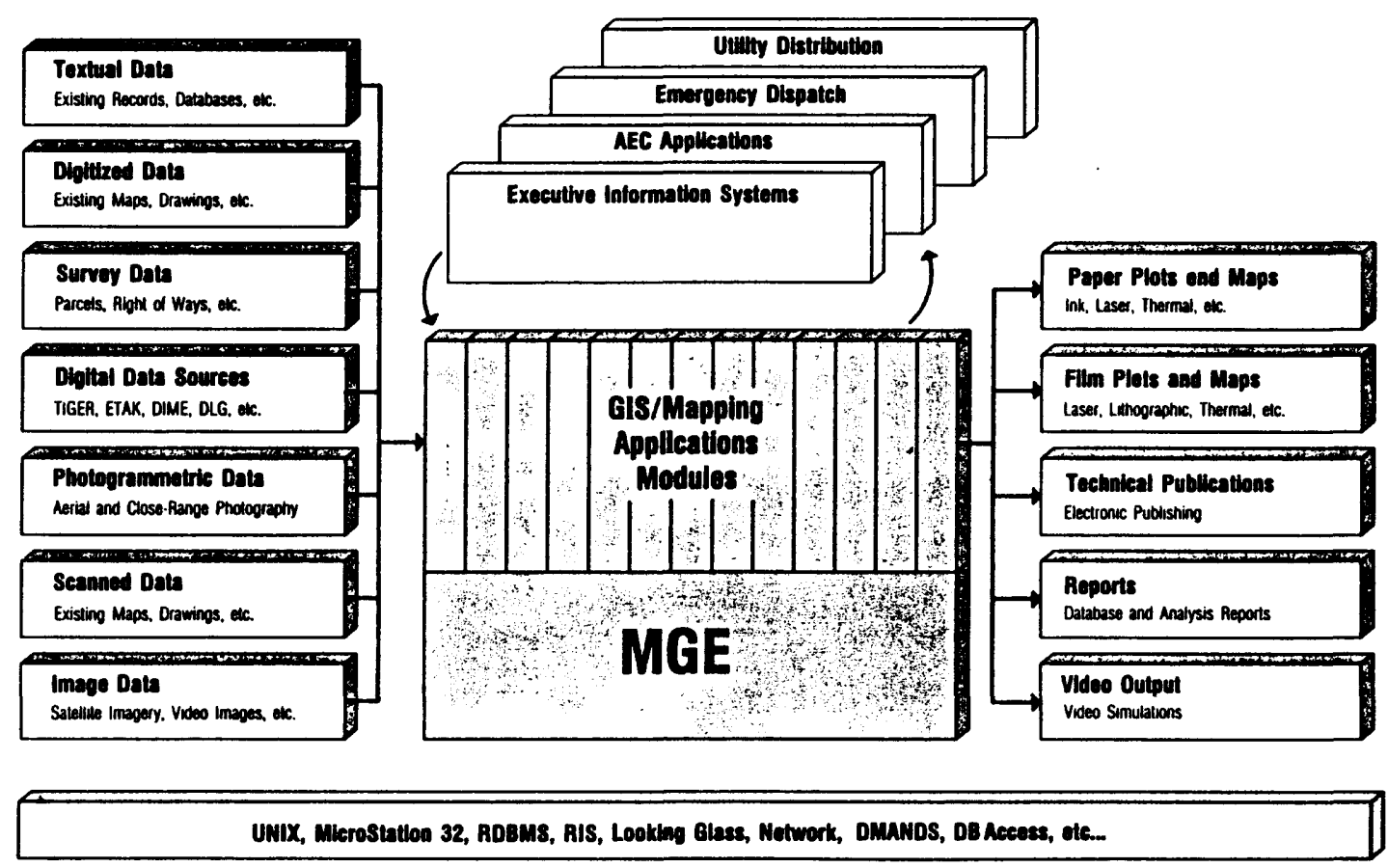

Figure 3. Integrated framework of Intergraph's Modular GIS Environment.

\section{ESRI's ARC/INFO}

ARC/NFO is a vector-based GIS for storing, analyzing, managing, and displaying geographic data. The ARC system stores cartographic data while the relational data base INFO stores attribute data. The ARC/INFO system was developed to be a generic GIS that could be applied to any geoprocessing task. It provides a large selection of commands that include six general capabilities, namely geographic database generation and management, geographic analysis, geographic database manipulation, database query, graphic display, and report generation. After data capture, ARC/INFO supports conversion to 50 map coordinate projections, as well as performing NAD27 to NAD83 geodetic datum adjustments.

Data editing capabilities include automatic detection and identification of digitizing errors, rubber sheeting, coordinate generalization, and feature snapping. ARC/INFO analysis functions include map overlay, buffer generation, map sheet manipulation, cartographic measurements, and tabular analysis. Graphic display and output can be controlled by tables that associate cartographic features with graphic symbols and shades. This software application currently operates at LGS on Sun SparcStation 1 system under UNIX.

\section{Networking}

Both GIS software packages are networked on LSU's campus-wide ethernet. MGE and the InterView 32c workstation are located at the Louisiana Geological Survey but are linked to an Oracle relational database on an Intergraph InterPro 6040 in the CADGIS Research Laboratory. This operation is completely transparent to the user, and allows the InterView $32 \mathrm{c}$ workstation to have additional free disk space for specific coastal data sets instead of database software.

The ARC/INFO software package is running on a Sun 4/390 Server that services five Sun SparcStation 1 Unix-based workstations. The Sun Server is located in the Southern Regional Climate Center in LSU's Department of Geography and Anthropology. Server-based Oracle is the relational data base used with 
ARC/INFO, thus making the system ARC/INFO/Oracle. The five Sun workstations are located in four University computer laboratories: 1) LGS's Coastal GIS Research Laboratory; 2) Geography and Anthropology's Mapping Sciences Computer Laboratory; 3) the Knowledge-based Laboratory in Agricultural Engineering; and 4) Geography and Anthropology's Southem Regional Climate Center. Only ARC/INFO executable files are swapped on local disk space for each of the Sun workstations; the five seats of ARC/INFO/Oracle can operate simultaneously. This coordinated networking effort among four laboratories is more efficient, saves money, improves communication, and provides better research. This type of networking is seen as the future for LCGISN.

\section{TECHNOLOGY TRANSFER}

An important component of LCGISN is the transfer of information about project development, progress, and related applications. In year 1 of the USGS/LGS cooperative agreement, a number of presentations and publications were completed to disseminate information about LCGISN and studies related to project development.

1. Don Davis and Randy McBride were interviewed by Bob Anderson for an article entitled "Louisiana Network to Organize Coastal Data" in the Morning Advocate, November 6, 1989.

2. Don Davis and Randy McBride presented a paper entitled "Mapping Louisiana's Coast and Establishing The Louisiana Coastal Geographic Information System", to the Louisiana Academy of Sciences 64th Annual Meeting, February 2, 1990, at Southem University, Baton Rouge, Louisiana.

3. Don Davis and others helped organize the Sixth Annual Remote Sensing and GIS Workshop on Remote Sensing and Geographic Information Systems for Coastal Management in Louisiana, Louisiana State University, Baton Rouge, April 17-19, 1990.

4. Don Davis presented a paper entitled "Introduction to the Louisiana Coastal GIS Network (LCGISN)", at the Sixth Annual Remote Sensing and GIS Workshop at Louisiana State University, Baton Rouge, April 17-19, 1990.

5. Randy McBride and Shea Penland presented a paper entitled "Shoreline Erosion Rates Pilot Study", at the Sixth Annual Remote Sensing and GIS Workshop at Louisiana State University, Baton Rouge, April 17-19, 1990.

6. Mark Bymes presented a paper entitled "Computer Mapping, Aerial Videotape Surveys, and GIS: An Integrated Approach to Developing a Shoreline Change Data Base", at the Great Lakes Shoreland Management Workshop, June 21-23, 1990, Cleveland, OH.

7. Mark Bymes gave a presentation to the Mississippi Gulf Coast Network Group entitled "Development of a Shoreline Change GIS for Coastal Mississippi", October 1990, Gulfport, MS.

8. Don Davis presented a paper entitled "Man at Risk in Louisiana's Coastal Zone: The Need for a Comprehensive GIS", at The Coastal Society's Twelfth International Conference, October 21-24, 1990, San Antonio, Texas.

9. Farrell Jones presented a paper entitled "Louisiana Coastal Geographic Information System Network", at The Coastal Society's Twelfth International Conference, October 21-24, 1990, San Antonio, Texas.

10. Mark Byrnes presented a paper entitled "Classification of Shoreline Change", at The Coastal Society's Twelfth International Conference, October 21-24, 1990, San Antonio, Texas.

11. Farrell Jones was an invited speaker at the Fall 1990 Intergraph Graphic Users Group held in New Orleans on October 7-11. He spoke to the Geographic Information System Special Interest Group about "The Varied GIS Activities at the LSU CADGIS Research Laboratory". He also participated in a panel discussion on the university's role in GIS research and training.

12. On October 2 LGS representatives met with seven representatives of regional government from Mississippi's coastal counties to discuss the concepts behind the LCGISN and its applications in Mississippi's coastal zone. 
13. On October 4 LGS representatives met with Bill Good and a delegation from Louisiana's Office of Coastal Restoration to discuss the concepts behind the LCGISN.

14. On October 16, LGS representatives met with Frederick C. Kopfler, Chief Scientist, U.S. Environmental Protection Agency, Gulf of Mexico Program, Stennis Space Center, Mississippi to discuss the concepts behind the LCGISN and its applications in the Gulf of Mexico Program.

15. Randy McBride and others submitted a paper entitled "Louisiana Coastal Geographic Information System Network (LCGISN): Access to Spatial Data", to Meridian (tentative publication date is mid 1991).

\section{SUMMARY AND FUTURE DIRECTION}

LCGISN consists of a management council, network core group, technical GIS group, and two independent advisory groups (coastal users and technical applications). One of the most important data sets identified for inclusion in LCGISN is a spatial index and bibliography of available data on Louisiana's coastal zone. Such an index will link true geographic location to maps, imagery, photographs, names, and bibliographic references to allow spatially defined geographic searches. An essential function of LCGISN is to connect existing GIS's and provide user access to spatial data available on different media.

During the first year, the prototype user interface was designed, tested, and refined using Hypercard running on a Macintosh. Unix-based workstations and GIS software were acquired and the network core group was connected through LSU's campus-wide ethernet. The management council and two independent advisory groups were established and integrated with LCGISN. The second year will involve the implementation of the user interface onto Unix-based workstations running $\mathrm{X}$-windows. The major data sets identified and ranked will be further assessed and, where possible, imported into the system to produce a working version of LCGISN. The third and fourth years will focus on perfecting the user interface, acquiring or programming translation routines, cataloging various types of media, importing additional digital data sets, developing a computer bulletin board, and regularly publishing a newsletter. By year five (1994), LCGISN will exist as a fully functioning stand-alone system. 


\section{REFERENCES}

Britsch, L.D. and E.G. Kemp III, 1990, Land loss rates: Mississippi River deltaic plain: Technical report GL-902, Vicksburg, MS, U.S. Army Corps of Engineers, 25 p.

Burrough, P.A., 1986, Principles of geographical information systems for land resource assessment: Monographs on Soil and Resources Survey Number 12, Clarendon Press, Oxford, Great Britain, 193 p.

Bymes, M.R., R.A. McBride, M.W. Hiland, and M. Crowell, 1991, Accuracy standards and development of a national shoreline change database: Coastal Sediments '91, American Society of Civil Engineers, v.1, p. $1027-1042$.

Davis, D.W., 1983, Economic and cultural consequences of land loss in Louisiana: Shore and Beach (October), p. 30-39.

Gagliano, S.M., KJ. Meyer-Arendt, and K.M. Wicker, 1981, Land loss in the Mississippi River deltaic plain: Transactions, Gulf Coast Association of Geological Societies, v. 31, p. 295-300.

Gosselink, J.G., C.L. Cordes, and J.W. Parsons, 1979, An ecological characterization study of the chenier plain coastal ecosystem of Louisiana and Texas: U.S. Fish and Wildlife Service, Office of Biological Services, Narrative report, FWS/OBS-78/9, v. 1, 302 p.

Holmes, D.O., 1990, Computers and geographic information access: Meridian, v. 4, p. 37-49.

Korte, G.B., 1991, GIS 1991: A Practitioner's Handbook: Design Strategies, Chamisal, NM, 67 p.

Logan, T.L. and N.A. Bryant, 1987, Spatial data software integration: merging CAD/CAD/mapping with GIS and image processing: Photogrammetric Engineering and Remote Sensing, v. 53(10), p. 1391-1395.

McBride, R.A., S. Penland, B. Jaffe, S.J. Williams, A.J. Sallenger, and K.A. Westphal, 1989, Erosion and deterioration of the Isles Dernieres barrier island arc, Louisiana, USA: 1853 to 1988: Transactions, Gulf Coast Association of Geological Societies, v. 39, p. 431-44.

Morgan, J.P., and P.B. Larimore, 1957, Changes in the Louisiana shoreline: Transactions, Gulf Coast Association of Geological Societies, v. 7, p. 303-10.

Penland, S. and R. Boyd, 1981, Shoreline changes on the Louisiana barrier coast: Oceans '81, Institute of Electrical and Electronic Engineers, p. 209-19.

Penland, S., H.H. Roberts, S.J. Williams, A.H. Sallenger, D.R. Cahoon, D.W. Davis, and C. G. Groat, 1990, Coastal land loss in Louisiana: Transactions, Gulf Coast Association of Geological Societies, v. 40, p. 67791.

Tumer, R.E. and D.R. Cahoon, eds., 1987, Causes of wetland loss in the coastal central Gulf of Mexico, Vol II: Technical Narrative, OCS Study/MMS 87-0120. Final report submitted to Minerals Management Service under contract no. 14-12-0001-30252 by the Louisiana Geological Survey, Baton Rouge, La. 400 p. 